\title{
Exploring Blended Learning in Higher Education: Different Definitions and Teachers' Perceptions
}



\section{INTRODUCTION}

The implementation of teaching and learning becomes more efficient and effective in this $21 \mathrm{st}$ century due to the advancements of technology. By introducing technology into teaching and learning, students and teachers are now able to connect in non-traditional ways which make the process of teaching and learning become more flexible and innovative (Caner, 2012). The higher education environments, in the last two decades, have witnessed the combining of information technologies and new pedagogies. For example, the widespread use of internet technologies helped teachers design and apply new generation learning environments that are authentic and more engaging. With the increasing importance of using communication technology in higher education, therefore, institutions must react to this change with understanding and vision to produce desired results (Garrison \& Kanuka, 2004). Leaders of higher education are challenged to position their institutions to meet growing demands and expectations of future students for higher quality learning. Universities need to provide more diverse cross-section of population that facilitate lifelong learning and include technology-based practice in the curriculum.

During the past decade, blended learning has been growing in demand and popularity in higher education and has become a widespread teaching phenomenon. This mode of learning is seen as an effective integration of the two main components, that is face-to-face and internet technology. Although blended learning has long been an educational approach that is still illdefined until recently, the interest in blended learning in the context of higher education have increased in the last two decades. This study will address the topic of blended learning in higher education. It will, particularly, explore the different definitions of blended learning and the 
views of teachers on blended learning courses. For the purposes of the study, the following definition will be used. Blended learning will be taken to refer to an approach that combines different delivery methods - online and face-to-face. This study will address the following research problem that is with universities around the world increasingly reorienting the provision of higher education towards blended learnings, there are challenges and limitations faced by the teachers in such learning methods.

This is a significant topic for several reasons. Firstly, with regards to higher education policy, due to massification, international competition, and technological developments, blended learning is seen as an effective way to cope these challenges and provide more flexible options to the range of ability and economic condition of students. Secondly, with regards to practitioner or professional concerns, providing the required support and resources for teachers in blended courses is essential so that practitioners need to know what can be learnt from the previous research on blended learning regarding pedagogical approaches. Lastly, people tend to look at specific technology in education and most research tend to be done in specific area of educational technology and it does not move to a broad area and does not really look at technology issues very critically and knowledgeably.

As such, the study will address the following questions:

1. What are the different definitions of blended learning shown in the existing literature?

2. What are experiences and perceptions of teachers on blended learning courses?

These will be addressed through a systematic study by locating papers on blended learning using specific databases. The aim of this work will be to reach a set of conclusions regarding how blended courses might be better implemented and fully benefit for all the stakeholders in higher education. This, it is hoped, can form the basis for subsequent research in this area.

\section{METHOD}

A systematic study is a literature study that is designed to locate, appraise and synthesis all published articles relating to specific research questions. The purpose of this study is to provide informative and evidence-based answers from various sources without setting up a new study. In other words, conducting systematic study requires a researcher to identify relevant studies, appraise their quality and then summarize their result using scientific methodology, which is focused, explicit, structured and must be transparent. Throughout the process of doing systematic study, any decisions have been made should be documented so that it can be replicated by other researchers. According to Boland, Cherry, and Dickson (2014), this approach is considered the best way to synthesis the findings of several studies investigating the same questions, whether from health, education, business and management, or other disciplines. Systematically studying the literature has been accepted as a legitimate research methodology since the early 1990s (Boland et al., 2014).

Different from traditional study, systematic study has specified aim and objectives with specific study questions. Hence, it is often named a "question-driven methodology" (Jesson, Matheson, \& Lacey, 2011). However, one of the limitations of the systematic methodology is that to do a good systematic study takes time and resources. It is often undertaken by more than one person. They are usually a team to do scanning, screening and quality assessment. There are several stages to take (Boland et al., 2014). The first stage is to define study questions and set the inclusion criteria. The second stage is to identify papers using specific databases and then read the title and the abstract of each article. The third stage is to screen the papers in the entirety, scanning for the key information that is needed for data extraction. This is where the quality criteria are applied, and the researchers sort out which papers to include and which to exclude. Then, the following stage is identifying and extracting relevant data from individual study. Data extraction is the process in which relevant data are presented in the tables. Finally, the last stage in doing a systematic study that is to analyze and synthesize all the data findings. If in the data 
extraction stage, the researchers unpacked each article, in the synthesis stage they must put them all together again. This is when the researcher tells a new story or make new connections. That is the researcher's contribution to knowledge or filling the gap in the literature.

In this study, the author reviewed empirical studies of blended learning in higher education published between 2000 and 2019. Although there has been extensive research on blended learning in higher education, this study only focused on studies that:

1) Primarily included blended learning, hybrid learning, and technology in higher education.

2) Occurred in taught graduate and not in fully online learning or distance education.

3) Was published between 2000, in which the biggest technology invention began until recent year, 2019.

4) Was written in English.

I began by searching studies published in specific databases, they are A+ Education, ERIC, ProQuest Education and Google Scholar. These databases were chosen as they provide journals that publish research in education field. The various combination of key terms that were used included blended learning, hybrid learning, technology, higher education, and teachers' perceptions. After examination of the full papers using different combinations of the key terms, 32 articles were meet all inclusion criteria and answer the research questions.

\section{RESULTS AND DISCUSSION}

\subsection{Different definitions of blended learning}

Based on the existing literature, the term blended learning is quite difficult to define since different people have a different understanding on it. Blended learning is different from distance learning or fully online learning. Bleed (2001) suggests that blended learning is seen as a way to redesign how courses in higher education are delivered by combining actual and virtual instruction, "brick and click". Hence, such courses include both traditional and online learning instructions and are typically run on campus. From the collected data, it can be classified that there are five different definitions of blended learning used by the researchers, namely:

\section{1) Combining classroom learning with computer-mediated instruction}

In higher educational research, the term blended learning is widely used referring to forms of teaching with using technology. It is combining classroom-based learning with computermediated instruction (Fibiger, Nielsen, Sorensen, \& Riis, 2005), (Bogaard, Graaff, \& Dekeyser, 2009), (Frantz et al., 2011), (Adriana, Gómez, \& Duart, 2012), (El-Mowafy, Kuhn, \& Snow, 2013), (Adams \& Blair, 2016), (Garcia, Abrego, \& Calvillo, 2014), (Tambouris, Zotou, \& Tarabanis, 2014). In a more detail description, Alammary, Sheard, and Carbone (2014) define blended learning as learning based on various combinations of classical face-to-face lectures, learning over the internet, and learning supported by other technologies. This kind of learning is designed to create the most effective learning environment. Geraghty (2016) develops a more precise definition that is the structure of blended learning involves a combination of selfdirected learning, online learning, critical thinking exercises, face-to-face workshops, lectures, and audio-visual elements. According to $\mathrm{Ng}$ (2008), face-to-face sessions include standard faceto-face lectures and other classroom activities, whereas online sessions include facilitating online discussion and giving feedback on the work done by students. Furthermore, Freeman and Johanson (2007) consider blended learning as combining face-to-face and online activities for students regardless of their mode of study. Blended learning also integrates other elements like online and traditional learning, different teaching methods, synchronous and asynchronous interactions, and group and individual learning activities.

\section{2) Reducing the number of face-to-face meetings to facilitate e-learning}

Although there are a plenty of definitions used to describe blended learning, most of definitions proposed by scholars are just variations of a few common themes. Caner (2012) claims that the 
blended learning is the combination of face-to-face and internet-based instruction in which the number of face-to-face meetings is reduced and facilitate the use of e-learning. In this model of teaching and learning, significant amounts of face-to-face elements are replaced by technologymediated teaching (Hoic-Bozic, Mornar, \& Boticki, 2009). In a similar way, Ocak (2011) views blended learning as a harmonious balance between using web-based technologies and face-toface instructor-led teaching in which some percentages of in-class activities is substituted by online activities. This mode of learning usually replaces some live events with online activities that should be completed by students on their own. Therefore, ICT is being used more to deliver course materials and facilitate students' learning.

\section{3) Integrating online with traditional face-to-face classes}

Another different definition is proposed by Picciano (2009) stating that blended learning is a kind of learning that integrates online with traditional class activities in a planned pedagogically valuable method. This is also supported by Donnelly (2016) and Akyol, Garrison, and Ozden (2009) who describe blended learning as the integration of face-to-face learning and online learning. This definition sounds simple, but in practice, Akyol et al. (2009) assert that it is not easy to create blended learning environment based on an instructional design perspective. Poorly designed learning environments often result in unsuccessful or unsatisfactory educational experiences. Similarly, (Hoadley, 2009) defines a hybrid course as a course that incorporates both face-to-face and online sessions. Some sessions may be synchronous or asynchronous depends on the availability of technology and the objectives of learning.

\section{4) Using ICT to complement the traditional form of learning}

Some disagree with the idea of reducing the amount of traditional learning in blended courses. Mitchell and Forer (2016), for example, argue that in blended courses, ICTs are just to complement, not replacing the traditional forms of learning. The use of ICTs, according to them, is to enable a more flexible and open learning environment. Therefore, blended courses allow students to take online activities as well as meet in a traditional classroom without any replacement in one of them. This is in line with the definition proposed by Kian-Sam and Lee (2008), Dengler (2016), Mtebe and Raphael (2013), and Carter, Pagliano, Knight, and Goldie (2016). As e-learning is a complement to the classroom learning, Dengler (2016) maintains that such learning can increase the opportunities for student participation and enhance the participation of students who may feel more inhibited to engage in discussions in a traditional classroom setting. The main benefits of this learning are students get opportunities to participate in learning and at their own pace, to receive written feedback, and also to connect with their classmates and teachers in different kind of learning environment. Braeckman, Fieuw, and Bogaert (2016) also claim that e-learning tool was to supplement the existing traditional course made up of lectures, tutorials, seminars, and workplace visits. As Oliver and Trigwell (2005) assert, the actual blended learning would involve students learning through experiencing variation aspects of what they are studying. This is based on the idea that learning will happen when variations are experienced by the learners. For that reason, the use of several teaching media may help students' learning in blended learning contexts.

\section{5) Flipped learning}

Using different term, the flipped classroom learning also refers to the similar approach as blended learning. It is an approach where online materials are given before the class so that face-to-face meeting is devoted for discussion and activities to develop students higher order thinking skills (Howitt \& Pegrum, 2015). Galway and Sciences (2015) considers flipping design to be a type of learning that put emphasis on active learning and problem-solving since in this learning students are encouraged to take ownership of their own learning. Besides, Johnston and Karafotias (2016) views flipped classroom is an effective teaching and learning method to meet diverse students' needs. It can engage students in innovative ways and use a range of modern teaching tools and approaches. 


\subsection{Teachers' experiences and perceptions on blended learning}

While there are many publications exploring students' perception of blended learning in higher education, only six studies from the collected data discuss what teachers' experiences and perceptions on teaching blended courses. From these studies, it can be identified that the reasons for teacher positive perceptions include increasing student engagement, promoting student interaction, offering flexibility, improving student interpersonal skills, and contributing to professional development.

\subsubsection{Positive perceptions}

1) Increasing student engagement in learning

Having taught Professional and Creative Writing courses for two years, Freeman and Johanson (2007) state that there are three key benefits of teaching in the blended mode. One of them is students have a strong engagement with the learning experience. The tasks offered in blended courses effectively encourage students to do revision after receiving their writing from the editor-student and are required to assess and adopt or reject the changes the editor has suggested. This act of evaluating also encourages higher level of critical thinking. In similar vein, Hoadley (2009) also found that students in the hybrid classes are motivated trying new things and learning from different modes. They are willing to learn from their peers even in less face-to-face setting. They are also eager to complete the assignments and review additional resources given by the teachers. More than that, Ocak (2011) argue that blended delivery not only offering teachers plenty ways for engaging students with meaningful learning activities, but also helping them to track student progress. Teachers can monitor student progress in blended setting by using different tools such as through online resources, weekly assignment, and various assessments.

\section{2) Promoting students' interaction}

By interviewing 117 faculty members from four different universities in Istanbul, Ankara and Izmir, Ocak (2011) identified some positive views on teaching blended courses. This includes promoting student interaction via computer-based communication tools like email and others. Not only interaction between students, one participated teacher also claimed that blended courses increase the interactions between students and the instructor. In the case of Shaqour (2014), online forum offered by blended courses has enabled female and male students to interact through Moodle as such interaction cannot be done in face-to-face setting in the Arab context. Lastly, Howitt and Pegrum (2015) assert that meaningful learning takes place when students actively participate in online interaction with their peers and engage in a collaborative learning process. The teacher, then, can focus on giving a hand on students who need extra help and more attention.

\section{3) Offering flexibility}

Blended mode is often named flexible mode since it gives some flexibility for not only students but also teachers. Due to this flexibility, teachers have an authority to develop and create learning activities that can be implemented in either traditional classes or online setting. This promotes teacher autonomy and personalization of teaching (Howitt \& Pegrum, 2015).

\section{4) Improving student interpersonal skill}

According to Freeman and Johanson (2007), the blended learning can improve students' interpersonal skills. As in their study students must edit other's work, students become much more cautious in making changes to their fellow's writing and more careful to explain the rationale for the changes they made. Through this activity, students ultimately develop their communication skills. 


\section{5) Contributing to professional development}

Using Moodle in blended learning also enhances the teaching and learning process in many ways (Shaqour, 2014). For example, teacher can add more resources to the course which result in making students' achievements better. With the availability of Moodle, it can assist teachers in creating different, meaningful engagement tasks and activities. Such work will contribute to the professional development of the teacher.

\subsubsection{Negative perceptions}

From teacher experiences, the key factors that bring negative perceptions of teaching blended courses associate with time commitment, technical problems, the complexity of instruction, the shifting role of teacher, and lack of effective communication.

\section{1) Time commitment}

The major issue on blended setting is centered on time for decisions and for development (Howitt \& Pegrum, 2015). First, extensive time is required for making an initial concept of blended course. Second, extra time is also needed to create the content of the course. For less experienced teachers, they may need more additional time for choosing numerous tools in elearning. Third, further time is required to design activities and workshops (Ocak, 2011). The teachers also need to provide appropriate activities to highlight the key concepts and connect to the assessment. Lastly, teachers still need sufficient time to mark students' work and give prompt feedback (Freeman \& Johanson, 2007). For many teachers, Hoadley (2009) points out that the flexibility does not mean less time to prepare the class. Teachers need to spend much time to work on the online learning. They may feel challenging and overwhelming at the same time. They need to facilitate students' online learning and encourage them to actively engage in online discussion forums. Although many teachers agreed that teaching in blended courses requires more time and effort, they admitted that the implementation of blended learning was worth it (Shaqour, 2014).

\section{2) Technical problems}

In their study, Bower, Kenney, Dalgarno, Lee, and Kennedy (2014) examined Australian and New Zealand educators' perception on their use of synchronous technologies. Uniting face-toface and remote students using rich media tools, such as video conferencing, web conferencing, and virtual world, teachers can facilitate efficient discussion and collaboration among students. However, one of the issues in the synchronous learning is the audio communication. If students want to use audio, for example, then there is a need for teacher to manage turn taking. Capturing student's voice sometime also creates a problem. From this experience, it can be concluded that technology is a crucial factor in blended synchronous setting. The computer and internet connections are seen to have a critical impact on the effectiveness of this program.

\section{3) The complexity of instruction}

Regarding the negative perceptions, Ocak (2011) also views that preparing the instruction in blended courses can be the main issue of the laziness to teach in this mode of delivery. Teaching blended courses is complicated as it requires expertise to make a good balance between face-toface section and online section. Blended course also requires teachers to adapt themselves to changing learning conditions because it needs more than combining two different delivery modes.

\section{4) The shifting role of teacher}

Blended teaching shifts teacher's role from teaching to tutoring and guiding (Ocak, 2011). Teaching in a blended course needs more responsibilities. Teachers must play these roles at the same time. Thus, many blended teachers think that this duty can be a critical issue for implementing blended mode. 


\section{5) Lack of effective communication}

Many of the concerns that teachers identified regarding blended learning are related to student communication. Teachers often find some challenges in promoting the use of online sessions of the blended courses. This lack of effective communication may cause a delay in exchanging ideas between the teachers and the students. Thus, Bower et al. (2014) suggested that the availability of support teacher is a need. If the main teacher presents in the virtual and physical environment, then the support teacher may help by ensuring that the communication is flowing well in both environments. The support role may also include helping students with technical problems.

\section{CONCLUSION}

A range of definitions suggested by researchers include combining classroom learning and online learning, reducing the number of face-to-face sessions to facilitate e-learning, integrating online with traditional classes, using technology to complement traditional form of learning, and flipped classroom learning. From these definitions, a common point is that in blended learning, technology plays a crucial role to facilitate and support learning. Because of the provision of technology, collaboration among students, synchronous online interaction, and flexibility to access materials can be ensured.

Regarding the teachers' perceptions of blended learning courses, blended learning can increase student engagement in learning, promote student interaction, provide flexible environment, help them improving students' skills, and contribute to their professional development. To achieve those potential benefits of blended learning, however, teachers encounter a number of challenges. The first and the major issue is related to time commitment. Teachers see that to participate in this setting, they need to spend a considerable amount of their time. The second greatest problem is associated with technical problems. The problem of slow internet connectivity hinders the effectiveness of this program. The complexity of instruction and the shifting role of teachers are two impediments that teachers need to handle. As blended design require an active role of teachers in both face-to-face and online settings, blended teachers have more responsibilities compared to traditional classroom teachers.

Giving fully supports for teachers is more important now as the role of teachers cannot be replaced by the availability of technologies. In the blended setting, teachers have more roles and responsibilities as they must be available in both settings, face-to-face and online. In face-toface classrooms, teachers' role may include manage face-to-face activities, encourage and support students' discussion, facilitate discussion, give feedback, mentor, and evaluator. Whereas in online setting, their roles can be content creators and facilitators, technologists, designers, administrators, advisers, assessors, and researchers. The shifting role of teacher from teaching to designing, planning, and guiding are sometimes considered as a challenge for some teachers. Therefore, there is a demand for institutions to assist teachers, for example, by providing at least one teacher assistant. The amount of assistance, of course, depends on the size of the blended classes. 


\section{REFERENCES}

Adams, R. V, \& Blair, E. (2016). The learner-generated podcast : engaging postgraduate engineering students in a mathematics-intensive course. Research in Post-Compulsory Education, 19(2), 132-146. https://doi.org/10.1080/13596748.2014.897502

Adriana, L., Gómez, O., \& Duart, J. M. (2012). A hybrid approach to university subject learning activities, 43(2), 259-271. https://doi.org/10.1111/j.1467-8535.2011.01175.x

Akyol, Z., Garrison, D. R., \& Ozden, M. Y. (2009). Online and Blended Communities of Inquiry: Exploring the Developmental and Perceptional Differences. International Review of Research in Open and Distance Learning, 10(6), 65-84.

Alammary, A., Sheard, J., \& Carbone, A. (2014). Blended learning in higher education: Three different design approaches. Australasian Journal of Educationa; Technology, 30(4), 440454.

Bogaard, M. Van Den, Graaff, E. De, \& Dekeyser, H. (2009). Making Connections : A Blended Learning Approach to the Delft UT International Master Students Introduction Program, $1-6$.

Boland, A., Cherry, M. G., \& Dickson, R. (2014). Doing a Systematic Review: A Student's Guide. London: SAGE.

Bower, M., Kenney, J., Dalgarno, B., Lee, M. J. W., \& Kennedy, G. E. (2014). Patterns and principles for blended synchronous learning : Engaging remote and face-to-face learners in rich-media real-time collaborative activities. Australasian Journal of Educational Technology, 30(3), 261-272.

Braeckman, L. A., Fieuw, A. M., \& Bogaert, H. J. Van. (2016). A Web- and Case-based Learning Program for Postgraduate Students in Occupational Medicine. International Journal of Occupational and Environmental Health, 14(1), 51-56. https://doi.org/10.1179/oeh.2008.14.1.51

Caner, M. (2012). The Definition of Blended Learning in Higher Education, 19-34. https://doi.org/10.4018/978-1-4666-0939-6.ch002

Carter, M. A., Pagliano, P., Knight, C., \& Goldie, D. (2016). An Exploratory Study in Postgraduate in Australia and Singapore Learning about Blended Learning through Students ' Experiences: In Mobile and blended learning innovations for improved learning outcomes (pp. 60-83). https://doi.org/10.4018/978-1-5225-0359-0.ch004

Dengler, M. (2016). Classroom Active Learning Complemented by an Online Discussion Forum to Teach Sustainability. Journal of Geography in Higher Education, 32(3), 481-494. https://doi.org/10.1080/03098260701514108

Donnelly, R. (2016). Blended problem - based learning for teacher education : lessons learnt, 13(2), 93-116. https://doi.org/10.1080/17439880600756621

El-Mowafy, A., Kuhn, M., \& Snow, T. (2013). Blended learning in higher education : Current and future challenges in surveying education. Issues in Educational Research, 23(2), 132150.

Fibiger, B., Nielsen, J., Sorensen, E. K., \& Riis, M. (2005). Program in ICT and Learning Project Learning and Virtual Collaboration - A Master, 3(1), 15-22.

Frantz, J., Himalowa, S., Karuguti, W., Kumurenzi, A., Mulenga, D., \& Sakala, M. (2011). Challenges and opportunities related to postgraduate evidence-based practice module using blended learning. AJHPE, 3(1), 15-18.

Freeman, R., \& Johanson, K. (2007). A case for blended and collaborative learning as strategies for teaching editing and publishing within a postgraduate writing program. Massey University.

Galway, L. P., \& Sciences, H. (2015). Student perceptions and lessons learned from flipping a master 's level environmental and occupational health course. Canadian Journal of Learning and Technology, 41(2), 1-16.

Garcia, A., Abrego, J., \& Calvillo, M. (2014). A Study of the of Hybrid Instructional Delivery 
for Graduate Students in an Educational Leadership Course. International Journal of ELearning and Distance Education, 29(1), 1-15.

Garrison, D. R., \& Kanuka, H. (2004). Blended learning : Uncovering its transformative potential in higher education, 7, 95-105. https://doi.org/10.1016/j.iheduc.2004.02.001

Geraghty, S. (2016). Evaluating postgraduate midwifery students ' experiences of a model of blended learning, 24(1), 60-63.

Hoadley, E. D. (2009). Teaching A Hybrid MBA Course : A Case Study In Information Technology from the Student Perspective. American Journal of Business Education, 2(6), 61-68.

Hoic-Bozic, N., Mornar, V., \& Boticki, I. (2009). A Blended Learning Approach to Course Design and Implementation. IEEE Transactions on Education, 52(1), 19-30.

Howitt, C., \& Pegrum, M. (2015). Implementing a flipped classroom approach in postgraduate education: An unexpected journey into pedagogical redesign. Australasian Journal of Educational Technology, 31(4), 458-469.

Jesson, J., Matheson, L., \& Lacey, M. F. (2011). Doing your literature review: Traditional and systematic techniques. Los Angeles: SAGE.

Johnston, N., \& Karafotias, T. (2016). Flipping the Classroom to Meet the Diverse Learning Needs of Library and Information Studies (LIS) Students. Journal of Education for Library and Information Science, 57(3), 226-238. https://doi.org/10.12783/issn.2328$2967 / 57 / 3 / 1$

Kian-Sam, H., \& Lee, J. A. C. (2008). Postgraduate students ' knowledge construction during asynchronous computer conferences in a blended learning environment: A Malaysian experience. Australasian Journal of Educational Technology, 24(1), 91-107.

Mitchell, P., \& Forer, P. (2016). Blended Learning: The Perceptions of First-year Geography Students. Journal of Geography in Higher Education, 34(1), 77-89. https://doi.org/10.1080/03098260902982484

Mtebe, J. S., \& Raphael, C. (2013). Students' experiences and challenges of blended learning at the University of Dar es Salaam, Tanzania. International Journal of Education and Development Using Information and Communication Technology, 9(3), 124-136.

Ng, E. M. W. (2008). Engaging Student Teachers in Peer Learning via a Blended Learning Environment. Issues in Informing Science and Information Technology, 5, 325-334.

Ocak, M. A. (2011). Computers \& Education Why are faculty members not teaching blended courses? Insights from faculty members. Computers \& Education, 56(3), 689-699. https://doi.org/10.1016/j.compedu.2010.10.011

Oliver, M., \& Trigwell, K. (2005). Can 'Blended Learning' Be Redeemed? E-Learning, 2(1), $17-26$.

Picciano, A. G. (2009). Blending with Purpose: The Multimodal Model. Journal of Asynchronous Learning Networks, 13(1), 7-18.

Shaqour, A. Z. (2014). Faculty Members' Views towards Blended Learning, the Case of a Najah National University Master Program Teachers in the College of Education and Teacher Preparation. International Journal of Humanities and Social Science, 4(7), 17-18.

Tambouris, E., Zotou, M., \& Tarabanis, K. (2014). Towards designing cognitively-enriched project-oriented courses within a blended problem-based learning context. Education and Information Technologies, 19(1), 61-86. https://doi.org/10.1007/s10639-012-9209-9 